\section{Eventos sociais como estratégia de atratividade e redução dos impactos da sazonalidade na hotelaria: o caso do Gran Marquise hotel, Fortaleza-CE}

\section{Social events as attractiveness strategy and seasonality impacts reduction in hospitality: Gran Marquise hotel's case, Fortaleza-}

\author{
Dambergh da Mota ${ }^{1}$ \\ Susana Dantas Coelho ${ }^{2}$
}

\begin{abstract}
Resumo
Os eventos sociais surgem na hotelaria como uma nova alternativa de elevação da receita hoteleira e redução dos impactos da sazonalidade turística, tendo em vista a diversidade de tipologias relacionadas a esse segmento. Os hotéis de grande porte têm se beneficiado de sua estrutura, conforto e elegância para atrair clientes, e utilizam o espaço de seus salões para a realização de cerimônias. O presente artigo caracterizou-se como um estudo de caso do Gran Marquise Hotel, Fortaleza-CE, o qual é referência local na realização de eventos sociais. A pesquisa foi relevante por estar relacionada a um mercado em ascensão, e buscou investigar quais os diferenciais oferecidos para os eventos sociais pelo Gran Marquise Hotel, Fortaleza-CE. Como metodologia, optou-se pela pesquisa bibliográfica associada à pesquisa descritiva de caráter exploratório, utilizando a coleta de dados por meio de pesquisa de campo e aplicação de questionário à Assistente de Eventos Sociais do hotel; e da Pesquisa de Qualidade de Eventos realizada com clientes de eventos sociais do hotel em questão. Os resultados apontaram quais os serviços oferecidos pelo hotel que podem ser visualizados como diferenciais competitivos, além de permitir conhecer a percepção do cliente em relação à satisfação nas fases de planejamento, organização e pós-evento.
\end{abstract}

Palavras-chave: Hotelaria; eventos sociais; sazonalidade turística.

\begin{abstract}
Social events arise in the hotel industry as a new alternative of increasing the hotels revenue and reducing the impacts of touristic seasonality, given the diversity of typologies related to that segment. The large hotels have benefitted from its structure, comfort and elegance to attract customers, and use the space of their halls for holding ceremonies. This article has characterized as a case study of Gran Marquise Hotel, Fortaleza-CE, which is a local reference in conducting social events. The research was important because it is related to a growing market, and aimed to investigate the differentials offered for social events by Gran Marquise Hotel, Fortaleza-CE. The methodology chosen was bibliographic research associated to descriptive research with exploratory character, using data collection through field survey and questionnaire application with the Assistant of Social Events of the hotel; and of the "Quality Event's Research" which is held with the social events' customers from the hotel in question. The results indicated which of the services offered by the hotel might be viewed as competitive advantages, besides to allow knowing the customer's perceptions related to its satisfaction on the phases of planning, organization and postevent.
\end{abstract}

Key-words: Hospitality; social events; touristic seasonality.

Professor Orientador de Estágio da Escola Estadual de Educação Profissional Marvin (Governo do Estado do Ceará em parceria com o Instituto CENTEC), Tecnólogo em Hotelaria pelo Instituto Federal de Educação, Ciência e Tecnologia do Ceará (IFCE). E-mail: dambergh.mota@gmail.com

2 Mestre em Gestão de Negócios Turísticos pela Universidade Estadual do Ceará (UECE), Docente e Coordenadora Pedagógica dos Cursos de Turismo, Hospitalidade e Lazer do Instituto Federal de Educação, Ciência e Tecnologia do Ceará (IFCE). E-mail: susana.dantas09@gmail.com

Artigo recebido em: 15 de abril de 2015. Artigo aceito em 02 de março de 2017. 


\section{INTRODUÇÃO}

O crescimento do mercado de eventos nas grandes capitais brasileiras vem proporcionando aos hotéis de grande porte a oportunidade de investir recursos para a construção de luxuosos salões em seus espaços físicos, visando à realização das diversas tipologias de eventos, entre elas, os eventos sociais, que surgem como uma possível estratégia de atrair clientes para reduzir os impactos da sazonalidade turística, além de elevar a receita geral. Para tal, faz-se necessário conhecer desejos e necessidades dos clientes, a fim de usar novas tecnologias, profissionalismo e comprometimento da empresa para garantir a satisfação do público.

Sabe-se que, atualmente, os eventos sociais representam uma nova tendência na oferta de serviços diferenciados pelo mercado hoteleiro. Em Fortaleza-CE, o Gran Marquise Hotel, referência local, destaca-se na realização desse nicho, como casamentos, cerimônias e bodas. Tomando como base de estudo esse empreendimento, questiona-se: como o segmento de eventos sociais se insere no contexto da hotelaria? Acredita-se que os hotéis têm executado seus eventos de forma integrada aos outros setores e fornecedores, além de realizar procedimentos de atendimento personalizado aos clientes, bem como, a exposição de orçamentos, contratos e avaliação dos serviços prestados durante os eventos. Além disso, percebe-se que os hotéis têm utilizado o crescimento dos eventos sociais como forma de atrair clientes de potencial e para reduzir os impactos que a sazonalidade turística causa na hotelaria.

Diante das informações supracitadas relacionadas a um mercado em constante ascensão e pela pouca produção acadêmica no segmento de eventos sociais em Fortaleza-CE, decidiu-se intitular o artigo com o tema: eventos sociais como estratégia de atratividade e redução dos impactos da sazonalidade na hotelaria, tendo como objeto de estudo o Gran Marquise Hotel, Fortaleza-CE. Tal pesquisa pode servir como subsídio para estudos futuros com temática similar.

O objetivo geral do artigo foi investigar quais os diferenciais estratégicos e atrativos oferecidos pelo Gran Marquise Hotel em seus eventos sociais. E como específicos, contextualizar o Gran Marquise Hotel no mercado de eventos de Fortaleza$\mathrm{CE}$; identificar os serviços oferecidos pelo hotel que podem ser visualizados como diferenciais; averiguar como os eventos sociais estão inseridos no hotel e conhecer a 
percepção do cliente em relação à satisfação nas fases de planejamento, organização e pós-evento.

Para alcançar os objetivos, optou-se pela pesquisa bibliográfica associada à pesquisa descritiva de caráter exploratório, utilizando a coleta de dados por meio de pesquisa de campo e aplicação de questionário. O levantamento bibliográfico teve início em janeiro, procedido da aplicação do questionário no mês de março de 2014, realizada em horário comercial, além de três visitas de campo.

Assim, foi elaborado um questionário semiestruturado dirigido à assistente de eventos sociais do Gran Marquise Hotel, com questionamentos voltados ao perfil do hotel frente aos eventos sociais, bem como a infraestrutura do setor, além de perguntas acerca do processo de captação de clientes e divulgação, benefícios, diferenciais competitivos e serviços oferecidos. Para a análise geral de resultados, buscou-se utilizar a Pesquisa de Qualidade de Eventos aplicada aos clientes, disponibilizada pelo hotel. Foi tomado como referência de estudo os meses de dezembro de 2013, fevereiro e março de 2014, e como amostra um total de 11 clientes, os quais responderam a pesquisa citada.

Foi dentro dessas perspectivas que se estruturou este artigo, dividido em seis seções principais: a introdutória, que consiste na apresentação da pesquisa e permite a compreensão da proposta, bem como, sua justificativa; a fundamentação teórica, que apresenta os conceitos relacionados ao tema; os materiais e métodos, que explicam a metodologia utilizada na pesquisa; resultados e discussões, que elenca a percepção dos clientes sobre as suas satisfações nas fases dos eventos sociais; considerações finais e proposições, com conclusão da pesquisa e as medidas a serem tomadas para melhorias constantes no Gran Marquise Hotel; e as referências utilizadas na pesquisa, as quais deram fundamentação teórica ao estudo.

\section{EVOLUÇÃO DO MERCADO DE EVENTOS E SUAS TENDÊNCIAS}

No contexto atual da globalização, o rápido desenvolvimento de marcas, produtos e serviços, fortalece o mercado de eventos, que muito além de reunir pessoas com finalidades diversas como comemorações, festividades, intercâmbio de conhecimentos e experiências, troca de informações etc., configura-se na atualidade como um mercado promissor, competitivo e repleto de criatividade, movimentando a 
economia e estimulando consumidores a investir em sonhos e emoções. O segmento de eventos mexe diretamente com os desejos e as necessidades dos clientes e é por esse motivo que Goidanich (1998) os define como sendo:

[...] acontecimentos criados e planejados para ocorrer em um lugar determinado e com espaço de tempo predefinido (...) com finalidades específicas, visando à preservação, à conquista ou à recuperação do público-alvo. Podem ser criados artificialmente, ocorrer espontaneamente, ou, ainda, ser provocados (GOIDANICH, 1998, p. 149).

Desde a Antiguidade, pessoas reunidas deslocavam-se de um local a outro com a intenção de tratar assuntos de interesse comum. Matias (2004) corrobora dizendo que os primeiros registros de eventos surgiram com os jogos olímpicos que aconteciam de quatro em quatro anos na Grécia, onde se reuniam milhares de pessoas de outras localidades com o intuito de se divertir durante os jogos.

As mudanças causadas pela Revolução Industrial trouxeram um crescimento do número de feiras e exposições, que tinham como característica marcante a maneira de mostrar e comercializar produtos produzidos pela indústria na intenção de manter os empregos. Essas feiras aconteciam ao ar livre e disponibilizavam aos compradores não só alimentos como também roupas e utensílios para casa.

Embora os eventos possuam uma tipologia que os caracterizam, estes são classificados de acordo com critérios e objetivos de cada um. Na visão de Tenan (2002), os eventos classificam-se quanto à frequência, localização, forma de participação, alcance do público, dimensão, objetivo, área de interesse, escopo geográfico e tipologia.

As diversas classificações de eventos fazem que o mercado se torne complexo e dependente de outros setores que fornecerão produtos e serviços decisivos para a realização dos mesmos. Para que ocorra a realização de um evento com êxito, faz-se necessário estabelecer parcerias com entidades, agências, associações e órgãos ligados aos eventos.

A cada ano, o setor de eventos ganha maior importância e larga expansão no mercado de turismo e na economia mundial. As vantagens de sua realização independem de tipologia e porte, épocas específicas do ano, alta ou baixa temporada. Dias (2003) corrobora afirmando que: “[...] é uma área pouco atingida em época de crise; não depende do regime governamental; gera divisa e emprego; motiva investimentos e melhoria; não é influenciada pela sazonalidade da atividade turística; atinge e traz benefícios para todos os outros segmentos do turismo" (DIAS, 2003, p. 4). 
A sazonalidade está presente no turismo em todo o mundo, sendo assim inevitável, principalmente para a hotelaria. Para Britto \& Fontes (2002), a sazonalidade no turismo é compreendida como a concentração das atividades turísticas em determinado espaço e tempo e a falta delas em outros períodos, de forma bastante característica. Segundo Petrocchi (2002), a sazonalidade acontece em decorrência de diversos fatores, entre eles os ciclos de atividades econômicas, as variações de clima, as férias escolares, as temporadas de festas e feriados etc. É desafio frequente às empresas de turismo atenuar os impactos da sazonalidade, pois a mesma afeta o equilíbrio financeiro, provocando queda de produtividade de fora para dentro.

A fim de reduzir tais impactos, as empresas de turismo utilizam um conjunto de ações de marketing, no campo da segmentação de mercado, da administração de preços e da montagem de ofertas promocionais. Britto \& Fontes (2002) destacam ainda algumas estratégias para a redução e gestão dos embaraços da sazonalidade turística de baixa estação, sendo elas:

[...] a criação e captação de eventos adequados a essa época; a prática de política de preços diferenciada nas estações; o desenvolvimento de novos mercados para aumento de fluxo de turistas numa localidade, como o próprio mercado de turismo de negócios; a utilização de produtos e serviços alinhados com as novas tecnologias; política de promoção e distribuição de produtos com força de penetração em mercados diversos; a identificação dos novos e atuais nichos de mercado e outros (BRITTO \& DIAS, 2002, p. 81 e 82).

Dessa forma, a redução dos efeitos da sazonalidade é um dos benefícios proporcionados pelos eventos. Como já citado, não dependem de épocas para existir e, por serem eventuais, Matsumoto (2005) defende que é essencial elaborar um bom cronograma de eventos, sendo fundamental que a proposta do evento tenha força por si, a fim de se estabelecer e conseguir despertar interesse ao público.

A competitividade do setor contribui para o aparecimento de novas tendências no segmento, como a realização de eventos sociais em hotéis, barracas de praia, restaurantes, salões de festas, entre outros. Para se compreender melhor a definição de competitividade, deve-se ter conhecimento de que: “[...] para acompanhar o processo concorrencial, as empresas devem ter um olho no passado - para fortalecer os acertos e não repetir erros; os pés firmes no presente - para posicionar-se com segurança diante da instabilidade do mercado; e um olhar atento para o futuro - para promover os ajustes necessários" (SILVA, 2001, p. 1).

Para Castelli (1996), "a competitividade depende da produtividade e esta, por 
sua vez, da qualidade". Portanto, a produtividade e a qualidade são fatores que visam à satisfação das pessoas e a sobrevivência da empresa, sendo esses objetivos essenciais de toda organização industrial ou comercial.

$\mathrm{Na}$ atividade de eventos, a qualidade em serviços é requisito fundamental para garantir a plena satisfação do cliente. Las Casas (2002) corrobora afirmando que a qualidade em serviços está ligada à satisfação, indicando assim que um serviço bem feito gera satisfação aos clientes que perceberão um serviço como de qualidade e voltarão a comprar ou indicar outras pessoas de seu relacionamento. Tal satisfação atendida pode ser a solução de um problema ocorrido, o atendimento de uma necessidade ou qualquer expectativa dentro do âmbito em questão.

Ao tratar de qualidade, entende-se esta, de acordo com Araújo (2007), como a busca pela perfeição visando agradar os clientes, que são cada vez mais exigentes e conscientes da quantidade de organizações, e o que elas têm para oferecer. Entende-se, então, que essa filosofia busca a eliminação do possível retrabalho e visa o defeito zero, assim as organizações permanecem no mercado e obtêm mais lucros.

Por sua vez, o autor citado afirma que a falta de qualidade representa perda de vendas, gera custos devido às reclamações dos clientes, o que ocasiona o retrabalho, e representa ameaça à sociedade, porque os produtos devem trazer benefícios aos seus consumidores e não o contrário.

Compreende-se, então, que uma ação mal planejada pode significar o fracasso total do evento, além de proporcionar imagem negativa da empresa organizadora. Dessa forma, torna-se fundamental que a empresa siga o planejamento inicial a fim de garantir o sucesso para a organização e, principalmente, para o cliente, além de, segundo Ford, Healton, Sturman (2012), investir no desenvolvimento dos seus recursos humanos, buscando a inovação constante dos serviços oferecidos, aumentando a adesão de novas tecnologias, realizando pesquisas de marketing, avaliando a performance dos eventos ocorridos, criando um sistema de gratificação por fidelização de clientes, e investindo em diferenciais.

Buscando então satisfazer as exigências dos clientes, proporcionando o diferencial a ser investido na festa e desenvolver serviços com qualidade, é necessário que: “[...] os administradores tenham uma sequência de procedimentos, como pesquisar, estabelecer uma cultura, desenvolver treinamento, criar um clima organizacional com o marketing interno, comunicar o plano e estabelecer mecanismos de controle. Todas 
essas atividades devem seguir o mercado e suas tendências" (LAS CASAS, 2002, p. 90).

Trata-se não apenas de atingir os resultados, mas de melhorá-los cada vez mais, buscando aperfeiçoamento contínuo daquilo que já é realizado. Assim, é tarefa das chefias remover os obstáculos que impedem as pessoas de produzir mais e melhor, pois a tangibilidade de um produto é tudo aquilo que o cliente sente e vê, por exemplo, a aparência física do hotel, tanto interna como externamente, entre outros fatores, como: conservação do prédio, jardins bem cuidados, a iluminação externa, a sinalização, bom acesso, uniforme, asseio e apresentação do pessoal, a decoração e limpeza dos ambientes. E é por meio desses componentes tangíveis que é captada ou percebida sua qualidade (CASTELLI, 1996).

\section{O GLAMOUR DA HOTELARIA E A DINAMICIDADE DOS EVENTOS SOCIAIS}

Segundo a Resolução Normativa 387/98, da EMBRATUR, empresa hoteleira é a pessoa jurídica que explore ou administre um meio de hospedagem e que tenha em seus objetivos sociais o exercício de atividade hoteleira; e hotel é o meio de hospedagem do tipo convencional e mais comum, normalmente localizado em perímetro urbano, e destinado a atender a turistas, tanto em viagens de lazer quanto em viagens de negócios.

Para a Organização Mundial do Turismo (2011), a hotelaria é entendida como o sistema comercial de bens materiais, cuja disposição deve satisfazer as necessidades básicas de alimentação e descanso de seus usuários fora de sua residência.

A hotelaria, atualmente inserida em um ambiente caracterizado pela instabilidade de mercados e alta competitividade, está exigindo que seus setores tenham estabelecido objetivos claros, pois vivem em um mundo de constantes transformações, cuja mudança é imprevisível.

De acordo com Dias \& Pimenta (2005), os eventos na hotelaria surgiram:

[...] na hotelaria internacional, mas supõe-se que o pioneiro tenha sido a inauguração do primeiro edifício de hotel do mundo, o City Hotel, em Nova York, no século XVIII. O hotel logo se tornou ponto de encontro da alta sociedade, que se reunia para conversar, discutir assuntos comuns, tomar chá e tratar de negócios, demonstrando que, desde o início, a hotelaria e os eventos interagem e se complementam (DIAS \& PIMENTA, 2005, p. 235). 
Já no Brasil, o marco inicial dos eventos na hotelaria ocorreu em 1923, com a construção do Hotel Copacabana Palace, no Rio de Janeiro, pois aconteciam nos salões do hotel os mais variados tipos de eventos, e que ainda hoje ele atrai grande número de participantes; e no mesmo ano, com a inauguração do Hotel Esplanada, em São Paulo, ostentando três luxuosos salões-restaurantes e salão de chá, que em pouco tempo tornou-se o principal ponto de encontro da elite paulistana.

Em Fortaleza-CE, a construção do Iracema Plaza Hotel, em 1951, primeiro hotel na orla marítima e inspirado na arquitetura luxuosa de Miami Beach, representa um marco na história dos eventos na cidade, pois se trata do primeiro hotel a possuir espaços destinados à realização de eventos na metade do século XX.

Os eventos, ao serem organizados, necessitam estar em adequação ao espaço físico inerente ao tipo do evento organizado. Quando os organizadores visualizam um hotel como espaço físico, parte das vezes pensa-se em um salão convencional, destinado às apresentações, palestras, seminários, entre outros. A disposição do espaço físico para eventos está diretamente relacionada ao projeto arquitetônico do hotel, que segundo Petrocchi (2002) é um fator decisivo na atratividade de clientes, criando diferenças relevantes e singulares que proporcionem o sucesso do hotel no mercado.

Com a construção dos grandes hotéis e o surgimento das redes hoteleiras, os hotéis passaram a inserir em seu planejamento arquitetônico, locais apropriados para atender principalmente a eventos sociais, empresariais e promocionais. Organizar eventos em hotéis é uma atividade em constante crescimento, tendo em vista que os hotéis que se disponibilizam a trabalhar com esse segmento de mercado têm obtido benefícios lucrativos, pois os eventos são uma alternativa de receitas para a hotelaria em geral.

Para Andrade (2002), não basta que o hotel disponha de bons espaços para que os serviços oferecidos sejam de excelência. Faz-se necessário coordenar todos os setores do hotel envolvidos no evento, garantindo assim o andamento do mesmo. Zanella (2006) afirma que a promoção de eventos nos períodos de baixa estação beneficia, também, a acomodação dos convidados e participantes nas dependências do hotel, além de melhorar a qualidade dos serviços, já que os funcionários poderão dedicar um tratamento mais personalizado aos clientes.

Dentro desse contexto estão os eventos sociais, entendidos como qualquer reunião que permita o entrosamento, confraternização e entretenimento entre os 
participantes, não tendo como objetivo informar, discutir, debater e tomar decisões. Sua principal característica é proporcionar uma ocasião favorável ao encontro de pessoas, congregando-as em torno de um objetivo específico que, simultaneamente, constitui o seu principal tema e justifica a sua realização.

Para Martin \& Rogers (2011), é possível utilizar as atividades de cunho social para, além de expandir de forma leve e descontraída a temática que permeia o evento, proporcionar uma experiência relacionada ao lugar que está sediando o evento.

Assim, o hotel utiliza esse benefício para promover o marketing e divulgação do seu espaço para a realização de futuros eventos, com temáticas semelhantes, perante clientes de potencial, os quais, de acordo com Britto \& Fontes (2002), constituem-se naquelas pessoas que se pretende atingir com a realização do evento, podendo esse público ser ampliado ou reduzido pela necessidade de sobrevivência da empresa hoteleira que está sediando o evento e prestando serviços ao mesmo.

Os eventos sociais se encontram em uma escala considerável de crescimento anual, visto que os tipos de cerimônias e confraternizações têm se diversificado e crescido em número. Dias \& Pimenta (2005) citam algumas tipologias desse nicho de eventos, como:

[...] almoço/jantar, baile de debutantes, banquete, batizado, brunch, casamento, coquetel, café da manhã, chá-bar, chá da tarde, chá-decozinha ou chá-de-panela, coffee-break, concurso de beleza, churrasco, funeral, festa infantil, festas populares tradicionais, festas temáticas, formatura, happy hour, noivado e vin d'honneur (DIAS \& PIMENTA, 2005, p. 237).

As empresas de organização de eventos são responsáveis por todo o aparato da festa, ou seja, desde o planejamento, orçamento, até a execução do evento. A terceirização de serviços e a parceria com outras empresas são fundamentais para que tudo aconteça no grande dia.

Vieira (2004) afirma que se torna importante que a empresa hoteleira se empenhe na prestação de serviços como forma de um diferencial, o que apresenta diversos enigmas, pois o ato de prestar serviços demanda características únicas.

De acordo com Souza (2003), os serviços definem-se como mercadoria isolada de características intangíveis que não se experimenta antes da aquisição, mas permite satisfações, que não podem ser estocada e que compense o investimento monetário pela realização dos anseios e necessidades do cliente que adquire. Defende ainda que o relacionamento entre hóspede e colaborador hoteleiro, o funcionário, pode ser encarado 
como um forte critério avaliado pelo consumidor para concluir o conceito sobre a qualidade do hotel.

Para a qualidade nos serviços, os estabelecimentos hoteleiros "devem almejar sempre estar em um patamar acima de que os outros estão" (VIEIRA, 2004, p. 82), ou seja, precisam oferecer produtos e serviços diferenciados que vão além das expectativas do cliente, ação de todos os colaboradores da empresa e em conjunto para que os objetivos sejam alcançados, assim como, também, a melhoria contínua.

A excelência em encantar o cliente vai além do que é oferecido a ele no evento proposto. Britto \& Fontes (2002) afirmam que é preciso criatividade e originalidade, pois esses são fatores que apresentam peculiaridades relativas ao formato e ao conteúdo do evento organizado.

O processo criativo em eventos implica a originalidade de sua idealização, concepção e execução. Assim, a premissa é que todo evento deve ser criado para ser único, envolver seu público-alvo, sensibilizar patrocinadores e trazer resultados positivos aos empreendedores. Os autores já citados defendem ainda que:

[...] ser criativo é ser capaz de criar, de produzir algo com ferramentas disponíveis. Quem cria não copia, mas pode transformar. A transformação é uma forma de criação. Ser original significa ser capaz de criar algo único. Quando se cria algo, está implícito que esse algo é novo, único, primeiro, original, diferenciado, nunca vista e que, desta forma, será capaz de atrair a curiosidade e gerar a motivação e o interesse das pessoas em conhecê-lo. Quando se cria algo novo, se está sendo criativo e original. A pessoa criativa move-se com habilidade no tempo e no espaço, transformando observações e experiências em novas ideias, e as ideias em ações criativas (BRITTO \& FONTES, 2002, p. 319).

Tais fatores, criatividade e originalidade, são primordiais para garantir encantamento e vislumbre aos olhos do cliente. Uma das melhores maneiras para garantir a satisfação do mesmo é conseguir atraí-lo e ultrapassar suas expectativas. Acerca do encantamento, Castelli (1996) reforça que, "satisfazer às necessidades dos clientes é o óbvio para as empresas que mergulharam na Qualidade Total. É preciso encantar o cliente, deixá-lo chocado pela excelência do serviço, pois é isto que faz a diferença, colocando a empresa na vitrine, em destaque perante os seus concorrentes".

Além disso, estabelecer uma relação interpessoal mais próxima com ele, criando laços de amizade e mostrando ao mesmo que ele é importante e sua contribuição, está alicerçada para o sucesso do negócio. 


\section{O STATUS DO GRAN MARQUISE HOTEL FRENTE AOS EVENTOS SOCIAIS}

De acordo com o Planejamento Estratégico do Gran Marquise Hotel (2008), o empreendimento é uma das empresas integrantes do Grupo Marquise, holding cearense que atua em 17 Estados brasileiros, comportando mais de três mil colaboradores. O hotel concentra sua identidade organizacional na missão de "assegurar a excelência de serviços através de produtos diferenciados, valorizando o crescimento humano e garantindo o retorno aos acionistas". Aspira, na visão de futuro, "ser reconhecido como o melhor hotel urbano no Nordeste, através da superação das expectativas dos clientes", concentrando seus valores na "ética; busca da melhoria contínua; confiabilidade na relação com clientes, fornecedores e colaboradores; capacitação e valorização do capital intelectual; responsabilidade social e comprometimento com normas e procedimentos".

O Gran Marquise Hotel está localizado na Avenida Beira Mar, Praia do Mucuripe. Dotado de arquitetura sofisticada e composto por 20 andares, o hotel dispõe de 230 unidades habitacionais. O hotel conta ainda com lobby bar, piscina, health club, business center, 15 salões de eventos com capacidade para até 1.700 pessoas e três restaurantes: Restaurante Mucuripe Grill, especializado em saladas e grelhados, Restaurante Mangostin, com especialidade na culinária asiática e Restaurante Nostradamus, de culinária contemporânea.

O estabelecimento foi vice-campeão do Prêmio Caio $2013^{1}$ na categoria hotel com espaço para eventos de médio porte, e foi vencedor do mesmo prêmio e categoria em anos anteriores. O hotel também foi destaque, em 2010, da categoria na última edição da Revista Quatro Rodas Ceará, da Editora Abril. Além disso, o hotel é considerado o "mais elegante" da capital cearense, e ocupa ainda a primeira posição no ranking dos melhores "para quem viaja a negócios" e dos que possuem "a melhor vista para o mar".

O Gran Marquise Hotel recebeu em 2011 o selo ISO 22000, a certificação de Gestão de Segurança de Alimentos, emitida pelos auditores da BRTÜV Avaliações da Qualidade S.A. Além desse novo reconhecimento, o Gran Marquise também renovou a

\footnotetext{
${ }^{1}$ O Prêmio Caio foi criado pela Revista dos Eventos, realizado pela Expo Editores, com a chancela da Academia Brasileira de Eventos e com o patrocínio do Ministério do Turismo. Sua função é qualificar e premiar todos os segmentos da cadeira produtiva do mercado de eventos no Brasil.
}

Revista Eletrônica Gestão e Serviços v.7, n. 2, pp. 1576-1601, Julho/Dezembro 2016.

ISSN Online: 2177-7284 e-mail: regs@metodista.br 
certificação ISO 9001, que atesta a qualidade dos serviços e instalações da empresa.

Pode-se afirmar que os diferenciais competitivos do Gran Marquise Hotel, dentro do mercado de Fortaleza, são muitos e se concentram, principalmente em suas classificações. O hotel tem se transformado em um dos espaços mais importantes do Ceará na realização de eventos sociais, como casamentos, confraternizações ou bodas, baile de debutantes e chás da tarde. Sua decoração e arquitetura conservam o requinte e o luxo de artistas internacionais renomados, traduzindo para os clientes o diferencial de sofisticação do hotel.

O requinte, a sofisticação e a alta gastronomia oferecida pelo estabelecimento em estudo, são alguns pontos que explicam o indicador de 80 casamentos que o Hotel Gran Marquise tem recebido por ano. O hotel objetivou com esse novo segmento de eventos atingir com qualidade e padrão internacional, tanto os eventos sociais, casamentos, formaturas e confraternizações, aniversários, bodas, como os eventos corporativos, como lançamentos de produtos, congressos, convenções, workshops, realizados externamente com empresas privadas ou públicas.

\section{MATERIAIS E MÉTODOS}

Como procedimento metodológico, optou-se pela pesquisa bibliográfica associada à pesquisa descritiva de caráter qualitativo, utilizando a coleta de dados por meio de pesquisa de campo e aplicação de questionário. O levantamento bibliográfico teve início em janeiro, procedido da aplicação do questionário no mês de março de 2014, realizada em horário comercial, além de três visitas de campo.

Foi elaborado um questionário semiestruturado dirigido à assistente de eventos sociais do Gran Marquise Hotel, Aline de Sousa Rodrigues, com questionamentos voltados ao perfil do hotel frente aos eventos sociais e seu histórico, bem como, à infraestrutura do setor, além de perguntas acerca do processo de captação de clientes e divulgação, benefícios, diferenciais competitivos e serviços oferecidos.

Para a análise geral de resultados, foi utilizada a Pesquisa de Qualidade de Eventos aplicada aos clientes, disponibilizada pelo hotel. Foram tomados como referência de estudo os meses de dezembro de 2013, fevereiro e março de 2014, e como amostra um total de 11 clientes, os quais responderam a pesquisa citada com questionamentos acerca dos serviços e instalações do hotel, atendimento comercial e 
operacional, serviço de alimentos e bebidas e infraestrutura dos salões de eventos.

\section{RESULTADOS E DISCUSSÕES}

Atualmente, o glamour, como charme, beleza e elegância, característico da hotelaria inerente aos hotéis de grande porte que possuem salões de eventos, está sendo utilizado pelos organizadores ou pelo próprio setor de eventos do hotel como espaço físico para eventos sociais como formaturas, 15 anos, casamentos e bodas. Esses eventos, além de utilizar o espaço físico, em alguns casos, estão agregados a outros serviços como alimentação tipo banquete, algumas vezes assinados por chefs de renome nacional, decoração e recursos humanos.

O Gran Marquise Hotel está inserido no mercado de eventos de Fortaleza-CE desde a sua fundação, possuindo 20 anos de história e experiências com o segmento de eventos sociais e corporativos, pois busca em sua essência o convívio direto com o cliente. Durante esse tempo, foram realizadas reformas nos salões de eventos, todas elas visando à melhoria dos espaços, bem como, ampliações. A reforma mais recente foi para o acréscimo dos banheiros de acessibilidade para cadeirantes em cada pavilhão de salões.

Uma importante evolução da sociedade nas últimas décadas foi a mudança na forma como as pessoas com deficiência são vistas e tratadas. Martin \& Roger (2011) afirmam que:

[...] o foco não é mais a deficiência em si (e, por consequência, as limitações dos deficientes), mas sim a acessibilidade. Isso implica a promoção da inclusão, e não da exclusão, além de um trabalho voltado para superar as principais barreiras que os deficientes enfrentam: ambientes inacessíveis, falta de informação apropriada, falta de consciência coletiva ou muitas atitudes negativas (MARTIN \& ROGER, 2011, p. 145).

Assim, uma abordagem mais acessível significa que as instalações dos salões para eventos devem ser projetadas de modo a satisfazer todas as necessidades de pessoas deficientes, e isso inclui desde cadeirantes e pessoas com problemas de visão e/ou audição, até pessoas com paralisia cerebral ou deformações faciais, bem como, as que apresentam dificuldades de aprendizagem. Para lidar com as necessidades de pessoas com alguma deficiência, faz-se necessário que as empresas de eventos, entre elas, os hotéis, sigam algumas recomendações, que ainda segundo Martin \& Roger (2011) são:

Revista Eletrônica Gestão e Serviços v.7, n. 2, pp. 1576-1601, Julho/Dezembro 2016.

ISSN Online: 2177-7284 e-mail: regs@metodista.br 
[...] estender aos clientes com deficiência a mesma abordagem otimista empregada com os outros clientes; ter cópias de todas as informações acerca do espaço para eventos em questão impressas em letras grandes, escritas em Braille e gravadas em áudio; [...] implantar pôsteres/monitores/mercadorias cujo foco é expressar uma calorosa acolhida a usuários de cadeira de rodas a uma altura de $900 \mathrm{~mm}$, em locais como pontos de inscrição, por exemplo; instalar rampas de acesso ligando o piso ao palco do salão; evitar colocar itens em locais onde eles possam representar perigo - ou ser facilmente deslocados por representantes cegos ou de visão reduzida (MARTIN \& ROGER, 2011, p. 146 e 147).

Os salões de eventos possuem sonorização, revestimento resistente ao corte e tração, ar-condicionado com controle remoto, além de mecanismos de adaptação, pois são utilizados tanto para os segmentos sociais como corporativos. Os 15 salões de eventos no hotel, divididos em três pavilhões, possuem capacidades diferentes, sendo cada salão escolhido de acordo com a necessidade do cliente em questão.

A divisão organizacional do setor de Eventos Sociais se dá entre a assistente e a gerente do setor, onde ambas são responsáveis pela parte de venda e captação de clientes. Além delas, existe a coordenadora do setor, que é responsável por toda a parte de organização, bem como, a liberação de entrada de materiais, fornecedores do evento e a contratação de garçons extras.

Das tipologias de eventos sociais existentes, o Gran Marquise Hotel trabalha com as seguintes: almoço, jantar, baile de 15 anos, batizado, bodas, brunch, casamento, coquetel, café da manhã, chá da tarde, festa infantil, formatura, noivado e vin d'honneur.

Britto \& Fontes (2002) afirmam que as bodas de casamento, ou o casamento em si, constituem cerimônias únicas e que devem ter planejamento bastante especial. Cada civilização histórica, em sua composição cultural, tinha formas diferentes de celebrar cada ocasião, sendo as bodas realizadas para comemorar anos de vida conjugal entre o casal, onde para cada ano de casamento celebrado existe uma nomenclatura diferenciada. Portanto, faz-se necessário que a equipe de organização de eventos conheça os anos referentes às bodas de casamento, pois cada um desses momentos é especial em sentimentos familiares e conjugais e tem características próprias.

Acerca da média de realização de eventos sociais no hotel, Rodrigues (2014) afirma serem feitos em média 12 eventos sociais mensais, sendo casamentos, bailes de 15 anos e jantares as tipologias mais trabalhadas. A tipologia mais comum é casamento (Figura 1), chegando a uma média de seis realizados por mês. O período do ano de 
maior concentração na realização de eventos sociais no hotel é o mês de dezembro, tendo como base estatística o ano de 2013, onde aconteceram 18 eventos sociais no mês em questão. Assim, percebe-se que não existe queda de realização desses eventos no hotel no período de alta temporada turística.

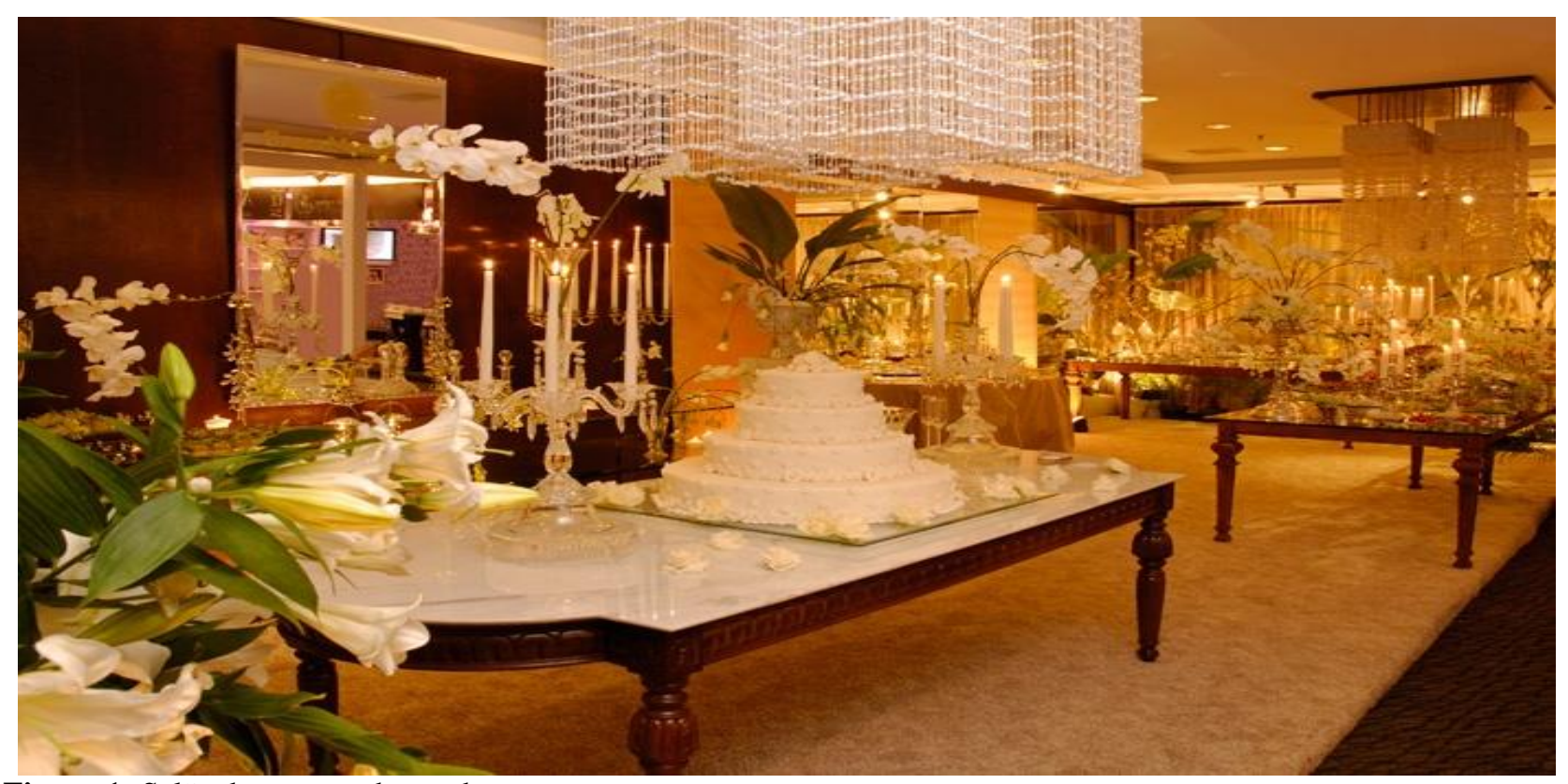

Figura 1: Salão de eventos decorado para casamento.

Fonte: Disponível em http://www.granmarquise.com.br/eventos-sociais. Acesso em 23 abr., 2014

O perfil do cliente trabalhado para as realizações de eventos sociais é o publico de classe alta, cujo processo de captação é feito pessoalmente com o cliente que vai até o hotel em busca do serviço oferecido. Os orçamentos solicitados pelo cliente são feitos apenas presencialmente, nenhuma informação acerca de valores é fornecida via telefone ou e-mail.

Para Zanella (2006), “o orçamento deverá ser expresso em várias alternativas para estudo e avaliação pelo interessado das opções e decisão final, e serve de base para o contrato de serviços". Durante esse processo de negociação do evento, consideram-se as cláusulas de risco relacionadas a serviços incluídos no cronograma de trabalho que deverão ser executados por terceiros.

Esse procedimento de apresentação de orçamentos é importante para esclarecer dúvidas e discutir eventuais alternativas em relação à programação do evento em questão. Ainda, segundo o autor citado, são necessárias algumas recomendações nessa 
fase:

[...] visitar as áreas ou dependências onde será realizado o evento, incluindo portarias de entrada e saída e áreas de circulação e estacionamento; após definidos os detalhes do evento, firmar um contrato de prestação de serviços ou utilizado o próprio formulário do orçamento aprovado, com assinaturas; para as providências de âmbito interno relacionadas com a execução do evento, utilizar o formulário relativo ao orçamento aprovado ou emitir uma ordem de serviço para o encaminhamento para todas as áreas envolvidas (ZANELLA, 2006, p. 124).

Para o controle de eventos sociais realizados, existe um calendário de eventos no hotel, cuja verificação de disponibilidade de datas é feita por meio do sistema integrado do estabelecimento. Além da captação pessoal, o hotel investe em divulgação pelo próprio website, revistas, folders e visitas a clientes de potencial, e também conta com o órgão Convention \& Visitors Bureaux na realização de ações de incentivo para a captação de novos eventos sociais.

Entre os outros setores do hotel, destacam-se o de Alimentos e Bebidas e o de Banquetes, que é o setor operacional responsável por executar os serviços que o cliente contratou. Esses setores se dinamizam junto ao setor de Eventos Sociais, contribuindo assim para o satisfatório andamento dos serviços contratados, bem como, o de alimentação, o qual já está incluso no contrato na forma de buffet.

O hotel oferece três tipos de propostas de alimentação para o evento social a ser realizado, todas elas com o serviço de volantes, canapés quentes e frios, bebidas, petitfours e finger-foods. Existe a proposta básica, que oferece jantar (entradas, saladas e pratos quentes); a intermediária, que dispõe de mesa de queijos ou de frios, jantar e estação de crepe; e a sofisticada, que possui mesa de queijos ou de frios, jantar, mesa de doces clássicos e uma estação temática (espaço japonês, italiano ou espanhol), além da opção de banquete "altas horas", que se caracteriza como um café da manhã servido fora de hora, onde é servido sopa de goulash com tortie e milk-shake de Ovomaltine com pão de queijo.

Toda a alimentação do evento é escolhida pelo cliente. O hotel apresenta as propostas existentes e as sugestões do chef, mas fica a cargo do cliente montar os sabores da proposta escolhida, de acordo com suas preferências. O cardápio é tradicionalmente constituído de uma entrada, prato principal, sobremesas, café e, em alguns casos, licores de diversos sabores e petit-fours. É mais apropriado optar por pratos da cozinha internacional, pois normalmente são bastante conhecidos e de 
unânime aceitação. Devem ser levados em consideração o clima da região e a climatização do ambiente do evento, pois comidas pesadas ou carregadas de temperos não podem ser servidas em locais com clima extremamente quente (BRITTO \& FONTES, 2002).

Além dos salões de eventos do hotel, os quais dispõem de uma cozinha de apoio em cada pavilhão, o cliente pode realizar seu evento social no Restaurante Mucuripe Grill, obedecendo ao critério de realizar seu evento fora do horário de funcionamento padrão do restaurante. No Restaurante Mucuripe Grill, ocorre diariamente o café da manhã para os hóspedes do hotel, bem como, a feijoada aos sábados e o almoço nordestino aos domingos para o público externo.

Os principais benefícios para o hotel ao promover eventos sociais são a captação de novos clientes, muitos deles vindos por indicação ou por terem participado de algum evento social no hotel como convidado; e também a elevação da receita do estabelecimento.

Já para o cliente, os benefícios em realizar eventos sociais no hotel estão ligados aos diferenciais oferecidos, como a não cobrança de taxa de rolha para vinho, uísque e espumante (que é uma taxa de serviço fixa para cada garrafa servida), taxa de energia de até $40.000 \mathrm{~W}$, hora extra, montagem de mesa e cadeiras, e quebra de material, como louças, copos e talheres.

Em seus eventos sociais, o Gran Marquise Hotel oferece serviços de mesas e cadeiras, palco e tablado de vidro para as cerimônias, equipe de atendimento nos toilets, estacionamento, manobrista e seguro; ficando a cargo do cliente contratante do evento pagar o valor do serviço de manobrista e seguro para os seus convidados ou deixar cada um pagar o seu, já que é um serviço terceirizado do hotel. Os serviços de banda, cerimonialista, decoração, som e iluminação, fotografia e vídeo, ficam a critério do cliente; porém, o hotel oferece indicações de empresas que trabalham com o serviço procurado e que já forneceram seus serviços em outros eventos realizados nos salões do hotel.

Tratando-se de casamentos, existe um diferencial marcante e ímpar que o Gran Marquise Hotel oferece à noiva: a partir de 200 convidados estabelecidos em contrato, os noivos ganham como cortesia a noite de núpcias e o day use no dia do casamento, onde são oferecidas trufas, flores, espumante, brinde especial, enxoval diferenciado, late check out até as 18 horas, café da manhã na suíte, além de cadeira de maquiagem para a 
noiva e luminárias.

O Gran Marquise Hotel ainda oferece como diferencial aos seus clientes hospedagem para convidados com tarifário diferenciado, além de toda a estrutura de banquetes e dos restaurantes do hotel. Para garantir o funcionamento dos serviços disponibilizados em seus eventos sociais, o hotel fideliza a terceirização de serviços de garçons e de limpeza.

Outros diferenciais que podem ser citados são possuir louças, talheres e taças importados com qualidade superior, sousplats de prata e toalhas de mesa em renda com acabamento sofisticado, lavanderia em caso de emergência, atendente pessoal para os noivos por toda a noite (para festas de casamento), serviço especializado em gala com dinners empratados, além de contar com o serviço de buffet individual por mesa (Figura 2).

Muitos podem ser os diferenciais incrementados para garantir o aluguel do espaço dos salões de eventos. Em uma época de disputa acirrada por uma quantidade maior de eventos, a inovação de produtos com foco no cliente é um dos diferenciais competitivos em ascensão. Muitos espaços para eventos estão investindo em seu "produto" físico para obter vantagens competitivas e também realçar sua orientação voltada para o cliente. Martin \& Rogers (2011) pontuam que:

[...] espaços para eventos competentes já estão investindo em cadeiras que podem ser empilhadas com facilidade, e também em mesas de tampo giratório, que podem ser limpas muito mais rapidamente que os móveis de sempre. Muitas das salas dedicadas a eventos são preparadas e depois revertidas à sua condição original por mulheres, e o tempo que se leva para a conclusão desse ciclo de tarefas é importante. Ter móveis mais leves e fáceis de manejar simplifica bastante o processo. O desafio para hotéis e centros de eventos é distinguir aquilo que não passa de uma febre entre seus clientes daquilo que é uma mudança cultural com impacto de longo prazo, e então investir de forma coerente no desenvolvimento do produto (MARTIN \& ROGER, 2011, p. 106). 
Figura 2: Mise en place das mesas.

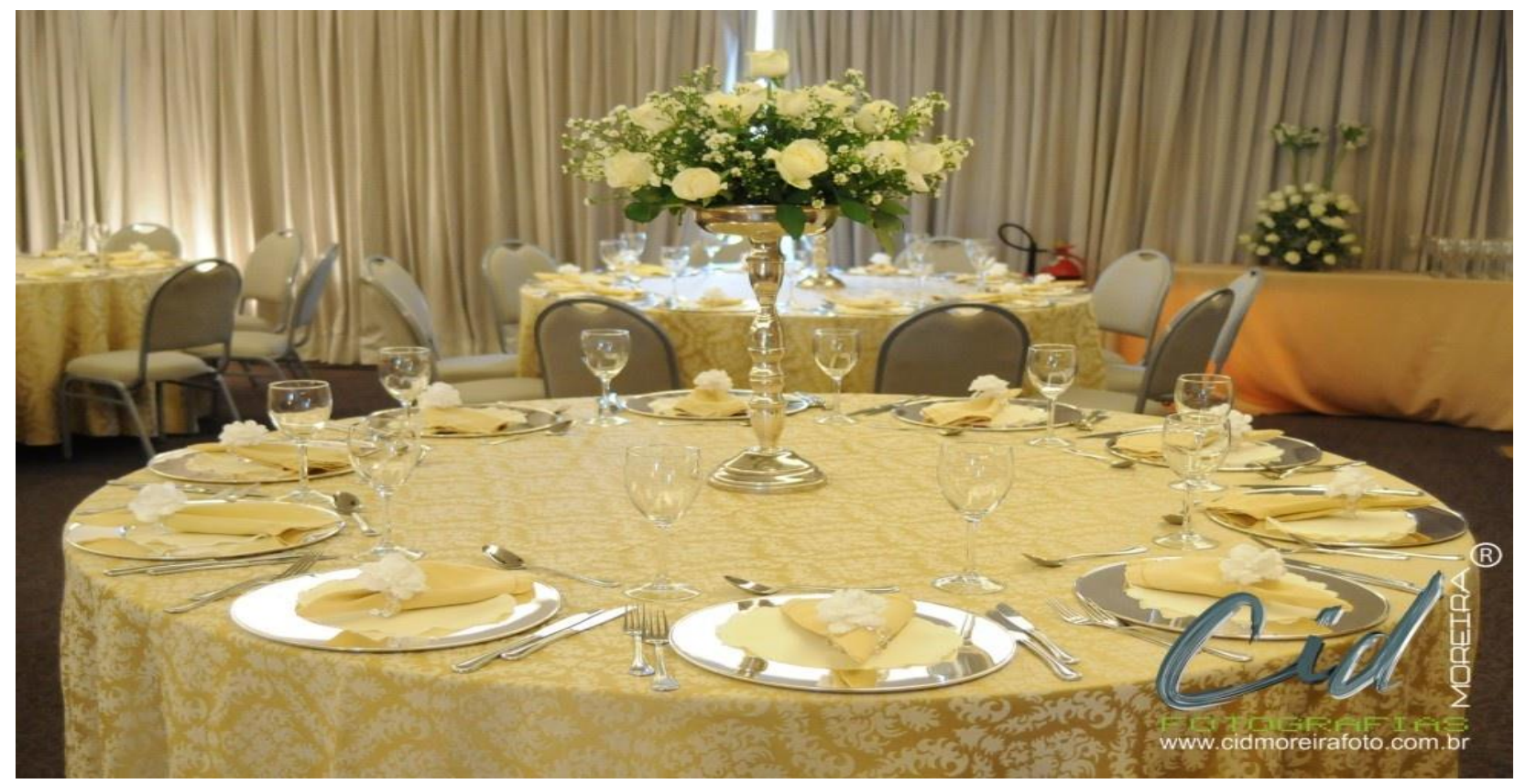

Fonte: Disponível em http://www.granmarquise.com.br/eventos-sociais. Acesso em 23 abr., 2014

Visando buscar melhorias constantes, o Gran Marquise Hotel aplica com seus clientes de eventos sociais a "Pesquisa de Qualidade em Eventos", onde os comentários e sugestões dos clientes proporcionam ao setor de eventos sociais a possibilidade de aperfeiçoar os serviços oferecidos durante as comemorações. A pesquisa em questão elenca quatro opções de respostas, entre elas: muito bom, bom, regular e ruim. Assim, o cliente tem a oportunidade de avaliar os serviços e instalações do hotel de forma geral; o atendimento comercial em relação à cortesia, receptividade, qualidade, cordialidade e presteza; o atendimento operacional acerca da agilidade, desenvolvimento, pontualidade e expectativa; o serviço de alimentos e bebidas em relação à sua apresentação, qualidade e variedade; e a infraestrutura dos salões de eventos em relação ao conforto e conservação dos ambientes, temperatura, iluminação, limpeza das salas e banheiros, e sinalização de acesso. Além disso, o cliente pode opinar acerca de suas expectativas e deixar comentários, sugestões ou algo que tenha chamado A sua atenção em especial.

Buscando conhecer a percepção do cliente de eventos sociais em relação à satisfação nas fases de planejamento, organização e pós-evento, foi tomado como base uma amostra de 11 clientes contratantes, referentes aos 34 eventos sociais ocorridos entres os meses de dezembro de 2013, fevereiro e março de 2014. O mês de janeiro de 2014 não foi levado em consideração, visto que não houve retorno de nenhum cliente 
sobre a Pesquisa de Qualidade de Eventos. Dessa forma, analisaram-se os resultados obtidos a partir da pesquisa já citada, identificando conceitos avaliados pelos clientes acerca dos serviços e instalações do hotel, do atendimento comercial e operacional, do serviço de alimentos e bebidas, bem como, da infraestrutura dos salões de eventos.

Observando o Gráfico 1, analisou-se que os 11 clientes pontuaram como muito bom os serviços do hotel, e que 10 deram a mesma pontuação acerca das instalações do estabelecimento. Apenas um cliente não avaliou o último ponto. De acordo com os resultados expostos, constata-se que a percepção dos clientes de eventos sociais com relação aos aspectos gerais do hotel, como suas instalações e serviços ofertados, é satisfatória, o que demonstra que o Gran Marquise Hotel agrada a seus clientes no que se refere ao espaço com serviços inclusos para a realização de eventos sociais.

Um dos aspectos levado em consideração para manter a competitividade dos espaços para eventos é o investimento no seu produto físico. Além disso, faz-se necessário a adoção de uma postura mais voltada para o cliente nas suas estratégias de marketing e vendas, assim como, na prestação de seus serviços. Tudo isso busca maximizar o retorno sobre os investimentos realizados por meio de abordagens específicas no setor de eventos, e também na gestão de receitas e negociação com os clientes (MARTIN \& ROGERS, 2011).

Gráfico 1: Percepção dos clientes de eventos sociais acerca dos aspectos gerais

\section{• Serviços do Hotel anstalações do Hotel}

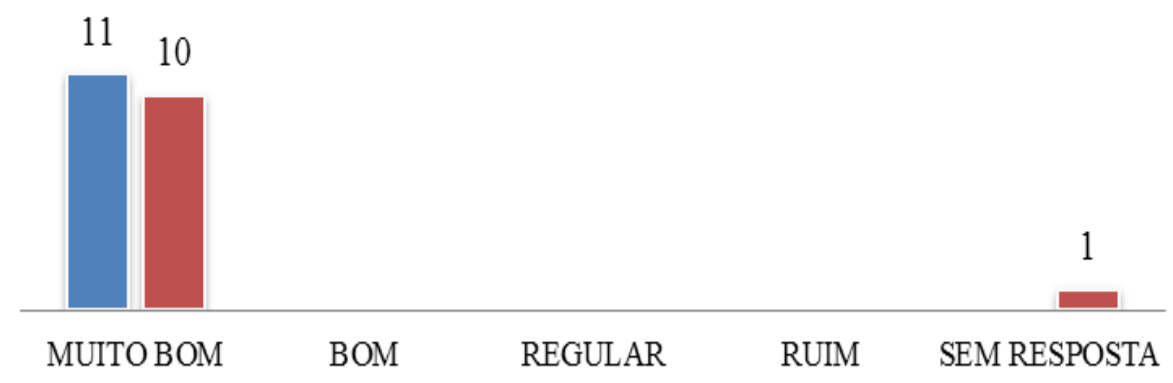

Fonte: Pesquisa de Qualidade de Eventos - Gran Marquise Hotel, 2014

Em relação ao atendimento comercial executado pelo hotel ao cliente, observouse que os 11 clientes que responderam à pesquisa classificaram como muito bom os cinco aspectos investigados, sendo eles: a cortesia, verificando se o setor de eventos 
sociais demonstra educação nos atendimentos prestados; a receptividade, buscando saber se o solicitado é respondido adequadamente; a qualidade, prezando pela rapidez e eficácia; a cordialidade, procurando exercer simplicidade no atendimento; e a presteza, investigando se o setor atende de imediato às solicitações feitas pelo cliente.

A partir disso, constatou-se que o processo de acompanhamento do Gran Marquise Hotel para com os clientes de eventos sociais e suas solicitações é realizado de forma satisfatória. Tal processo está ligado diretamente ao marketing de relacionamento, e é fundamental para garantir a ascensão do mercado investigado no hotel.

Petrocchi (2002) afirma que "o empreendimento hoteleiro, como um sistema aberto complexo, tem sua sobrevivência ligada diretamente ao seu relacionamento com o hóspede, seu cliente". A forma e qualidade dessa relação são estratégias que devem ser minuciosamente planejadas e realizadas, pois delas depende o sucesso do empreendimento. O marketing de relacionamento busca preservar o cliente, alcançando um nível elevado de atendimento e incentivando a repetição ou divulgação do serviço, por meio de estímulos em bonificações e tratamentos diferenciados.

A forma como o procedimento de venda do espaço dos salões de eventos é realizada será responsável pela conquista do cliente, desde seu acolhimento até o planejamento e organização do evento. Isso proporcionará ao hotel a prospecção de futuros clientes, os quais buscarão os serviços e instalações do estabelecimento por indicações de outros que já realizaram algum evento social nas dependências do local.

$\mathrm{Na}$ análise do atendimento operacional, buscou-se averiguar a percepção do cliente acerca da execução dos processos durante o evento. Tomou-se como base o Gráfico 2, dos 11 clientes em questão, onde todos pontuaram como muito bom os aspectos agilidade e desenvolvimento, relacionados ao pronto atendimento e presteza, respectivamente. Com relação à pontualidade e expectativa, sendo essa ligada à execução dos serviços acordados, a maior parte dos clientes classificou como muito bom; dois deram conceito bom à pontualidade, um deu o mesmo conceito para expectativa, e um não avaliou a mesma. 
Gráfico 2: Percepção dos clientes de eventos sociais acerca do atendimento operacional

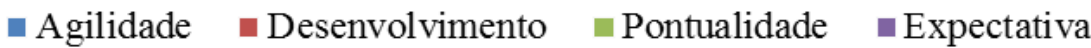
1111

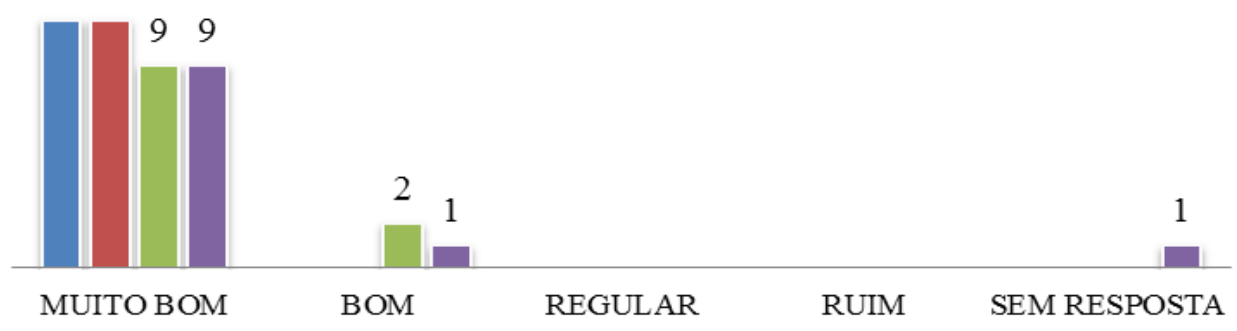

Fonte: Pesquisa de Qualidade de Eventos - Gran Marquise Hotel, 2014

Em linhas gerais, os conceitos escolhidos pelos clientes para avaliarem o atendimento das operações executadas durante os eventos sociais foram satisfatórios, tendo em vista que, algumas vezes, acontecem dois ou mais eventos sociais nos salões do hotel no mesmo dia. A partir dessa constatação, pôde-se afirmar que o Gran Marquise Hotel cumpre de maneira adequada e justa as cláusulas contratuais acordadas com seus clientes, atingindo as expectativas dos mesmos com relação aos serviços prestados nos eventos.

Quanto ao serviço de alimentos e bebidas, todos os clientes em estudo classificaram os aspectos apresentação, qualidade e variedade com conceito muito bom. Com essa análise, constatou-se que o serviço de alimentos e bebidas, incluso na venda inicial para o cliente por meio da escolha de uma das propostas de alimentação, mostrase satisfatório, atingindo as expectativas do público em questão.

Para averiguar a percepção dos clientes sobre a infraestrutura dos salões de eventos, faz-se necessário atentar para o Gráfico 3, logo a seguir. Dos 11 clientes investigados, a maioria conceituou como muito bom os aspectos conforto e conservação dos ambientes, limpeza dos salões e sinalização de acesso; enquanto três deram aos mesmos aspectos conceito bom. Sobre a temperatura do salão, sete pontuaram como muito bom, três como bom, um como regular e um não respondeu. Para o aspecto iluminação do salão, nove clientes classificaram como muito bom, enquanto outros dois como bom. 
Gráfico 3: Percepção dos clientes de eventos sociais acerca da infraestrutura dos salões

$$
\begin{aligned}
& \text { • Conforto e conservação — Temperatura = Iluminação } \\
& \text { घ Limpeza } \quad \text { - Sinalização de acesso }
\end{aligned}
$$

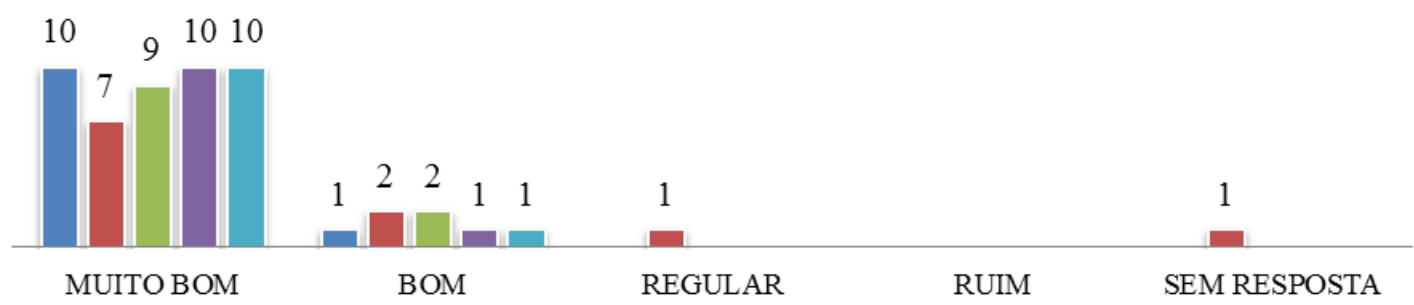

Fonte: Pesquisa de Qualidade de Eventos - Gran Marquise Hotel, 2014

Dos aspectos listados, percebe-se que o único não atendido de forma satisfatória pelo Gran Marquise Hotel é a temperatura do salão. Para eliminar tal problema, é necessário adotar um método e ferramentas apropriadas envolvendo todos os funcionários responsáveis, a fim de identificar tais causas e saná-las (CASTELLI, 1996). Proporcionar temperatura, iluminação e ventilação agradáveis, são um dos quesitos básicos para a organização física de evento, a fim de garantir seu sucesso (BRITTO \& FONTES, 2002). Dentro do possível apresentado pelo espaço de sua realização, a organização física de qualquer evento deve proporcionar o sucesso dos objetivos traçados, facilitar a circulação e o encontro de pessoas, oferecendo conforto e segurança, além de uma apresentação agradável e interessante.

\section{CONSIDERAÇÕES FINAIS E PROPOSIÇÕES}

O caso apresentado investigou como o crescente mercado de eventos sociais está inserido no Gran Marquise Hotel, Fortaleza-CE, identificando os serviços oferecidos que são visualizados como diferenciais, e conhecendo a percepção de seus clientes em relação ao grau de satisfação nas fases de planejamento, organização e pós-evento. Para a obtenção dos dados, foi realizada a aplicação de questionário com a assistente de eventos sociais do hotel, além da análise qualitativa da Pesquisa de Qualidade de Eventos aplicada pelo estabelecimento aos seus clientes.

A partir dos resultados obtidos, foi possível perceber que o setor de Eventos Sociais organiza-se no hotel estudado em vendas, operação de banquetes e gerência, além de conhecer que as tipologias mais trabalhadas são casamentos e bodas. Também 
foi averiguado que o setor de Alimentos \& Bebidas trabalha em dinamicidade com o setor de Eventos Sociais, garantindo a execução dos serviços acordados em uma das três propostas de alimentação escolhida pelo cliente no ato da venda do espaço do salão.

Muitos foram os benefícios identificados na realização de eventos sociais, tanto para o hotel como para o cliente. Para o hotel, esse segmento é mais uma alternativa para elevar a receita anual e reduzir os impactos da sazonalidade turística. Já o cliente, foca os serviços diferenciais oferecidos, como a não cobrança de taxas extras, cortesias, tarifário diferenciado para convidados em caso de hospedagem, além de materiais com qualidade superior.

Para cumprir o que se propõe, no que tange à qualidade de serviços por meio de produtos diferenciados e manter a responsabilidade social e o comprometimento com normas e procedimentos, o Gran Marquise Hotel procura garantir a qualidade total. Para isso, torna-se necessário a busca constante por diferenciais inovadores capazes de fidelizar e atrair novos clientes, a fim de proporcionar recordações satisfatórias, já que isso é uma das premissas dos eventos sociais; além de investir no feedback do cliente a fim de garantir melhorias constantes.

Como proposições, buscar melhorar, cada dia mais, atendendo às necessidades dos clientes e procurando novidades, tendências e modismos do mercado brasileiro e mundial no que se refere à qualidade e diferencial no atendimento. Além disso, investir ainda mais em criatividade e originalidade de serviços oferecidos, a fim de tornar o evento uma experiência única na vida de cada cliente, de acordo com suas necessidades e expectativas, proporcionando, acima de tudo, um ambiente agradável e divertido. Para isso, faz-se necessário desenvolver estratégias de decoração, seja ela ambientação temática ou convencional, que visam atingir o objetivo de cada evento, englobando, além da decoração cenográfica, a escolha de cardápios temáticos, entre outros.

Também deve-se buscar solucionar problemas mencionados por clientes para resolvê-los definitivamente. Observou-se na pesquisa que houve insatisfação com relação à temperatura do salão, o que deve ser sanado o mais rápido possível, tendo em vista a simplicidade do problema. E ainda, propõe-se investir em ações sustentáveis, como: preservação ambiental, iluminação e ventilação, aquecimento, segurança e automação; tomando como base a consciência ecológica e a racionalização de investimentos e dos custos operacionais.

Assim, constatou-se que o Gran Marquise Hotel, com todos os diferenciais 
competitivos e serviços exclusivos, coloca-se em uma posição favorável na percepção de seus clientes de eventos sociais, fato esse que tende a proporcionar ao estabelecimento a sua contínua colocação nesse mercado dinâmico e em ascensão, cujo charme, beleza e elegância são elementos ímpares para o seu glamour e atratividade.

Diante dos dados expostos, a hipótese inicial foi confirmada e os objetivos foram atendidos em sua totalidade. Além disso, os resultados obtidos foram satisfatórios e positivos para ambas as partes, hotel e cliente.

É importante ressaltar que a pesquisa contou com a disponibilidade dos funcionários do setor de eventos sociais do hotel, que disponibilizou com presteza dados solicitados para atender aos objetivos iniciais.

\section{REFERÊNCIAS}

ANDRADE, Renato Brenol. Manual de Eventos, Caxias do Sul (RS): Edcus, 2002.

ARAUJO, Luiz César G. Organização, sistemas e métodos e as tecnologias de gestão organizacional: arquitetura organizacional, benchmarking, empowerment, gestão pela qualidade total, reengenharia, 3. ed., São Paulo: Atlas, 2007, v. 1.

BRITO, Janaina; FONTES, Nena. Estratégias para eventos: uma ótica do marketing e do turismo, São Paulo: Aleph, 2002.

CASTELLI, Geraldo. Excelência em hotelaria: uma abordagem prática, Rio de Janeiro: Qualitymark, 1996.

DIAS, R.; AGUIAR, M. R. Fundamentos do Turismo, São Paulo: Alínea, 2003.

DIAS, Reinaldo; PIMENTA, Maria Alzira (Orgs.). A Gestão de hotelaria e turismo, São Paulo (SP): Pearson Prentice Hall, 2005.

FORD, Robert C.; HEALTON, Cherril P.; STURMAN, Michael C. Managing Quality Service in Hospitality: How Organizations Achieve Excellence in the Guest Experience. Delmar Cengage Learning, 2012.

GOIDANICH, Karin Leyser. Turismo de Eventos, Porto Alegre: Sebrae, 1998.

GRAN MARQUISE HOTEL, Planejamento Estratégico, 2008.

LAS CASAS, Alexandre L. Marketing de serviços, 3. ed., São Paulo: Atlas, 2002.

MARTIN, Vanessa; ROGERS, Tony. Eventos: planejamento, organização e mercados [trad. Ana Paula Spolon]. Coleção Eduardo Sanovicz de Turismo, Rio de Janeiro: Elsevier, 2011.

Revista Eletrônica Gestão e Serviços v.7, n. 2, pp. 1576-1601, Julho/Dezembro 2016.

ISSN Online: 2177-7284 e-mail: regs@metodista.br 
MATIAS, Marlene. Organização de Eventos: procedimentos e técnicas, 3. ed., Barueri (SP): Manole, 2004.

MATSUMOTO, D. Turismo de Megaeventos e o meio urbano (Trabalho de Conclusão de Curso). ECA - Escola de Comunicação e Artes. Curso para Bacharel em Turismo, Universidade de São Paulo, São Paulo, 2005.

ORGANIZAÇÃO MUNDIAL DO TURISMO. Introdução ao Turismo, São Paulo: Roca, 2011.

PETROCCHI, Mario. Hotelaria: planejamento e gestão, São Paulo (SP): Futura, 2002.

RODRIGUES, Aline de Sousa. Entrevista [mar. 2014]. Entrevistador: Dambergh da Mota, Fortaleza, 2014, 1 arquivo .mp3 (60 min).

SILVA, C. L. Competitividade: mais que um objetivo, uma necessidade, Revista FAE BUSINESS, n. 1, nov., 2001.

SOUZA, A. J. Os serviços no setor da hospitalidade: criação de valor para os clientes de hotelaria. In: CIRILO, L. (Org.). Administração hoteleira: desafios e tendências para o século XXI, São Paulo: DVS Editora, 2003.

TENAN, Ilka Paulete Svissero. Eventos, São Paulo: Aleph, 2002 (Coleção ABC do Turismo).

VIERA, E. V. Qualidade em Serviços Hoteleiros: a Satisfação do cliente é função de todos, Caxias do Sul: EDUCS, 2004.

ZANELLA, Luiz Carlos. Manual de organização de eventos: planejamento e operacionalização, 3. ed., 2. reimpr., São Paulo: Atlas, 2006. 